\title{
A case of spider phobia in a congenitally blind person
}

\author{
Frauke Musial $^{\mathrm{a}, \mathrm{b}}$, Iris-Tatjana Kolassa ${ }^{\mathrm{a}, \mathrm{c}, *}$, Sandra Sülzenbrück ${ }^{\mathrm{a}, \mathrm{d}}$, \\ Wolfgang H.R. Miltner ${ }^{\mathrm{a}}$ \\ ${ }^{a}$ Institute of Psychology, Biological and Clinical Psychology, University of Jena, Germany \\ ${ }^{\mathrm{b}}$ Department of Complementary and Integrative Medicine, Kliniken Essen Mitte, University of Duisburg Essen, Germany \\ ${ }^{\mathrm{c}}$ Department of Psychology, Clinical and Neuropsychology, University of Konstanz, Germany \\ ${ }^{\mathrm{d}}$ Institute for Occupational Physiology, University of Dortmund, Germany
}

\begin{abstract}
Vision is the key sensory system in humans, leading to the implicit assumption that the acquisition of spider phobia is predominantly mediated through the visual pathway. We report on a congenitally blind person with spider phobia, showing that the acquisition of spider phobia does not necessarily depend on visual cues.
\end{abstract}

Keywords: Spider phobia; Congenital blindness; Acquisition of phobias

\section{Introduction}

The term "phobia" describes a marked and persistent fear of circumscribed objects or situations (American Psychiatric Association, 1994). Approximately 10\% to $12 \%$ of the general adult population suffer from specific phobias (Mineka and Öhman, 2002), most commonly fears of spiders, snakes, and heights. It has been suggested that at least some of these fears derive from an inborn preparedness to react pre-attentively and with high priority to potentially threatening stimuli. This innate preparedness is thought to originate from the actual threat that some objects and circumstances (e.g., spiders, snakes, and heights) posed for the survival and

\footnotetext{
* Corresponding author. Biological and Clinical Psychology, Department of Psychology, University of Konstanz, P.O. Box 5560, D25, 78457 Konstanz, Germany. Tel.: +49 753188 4003; fax: +49 7531884601 .

E mail address: Iris.Kolassa@uni konstanz.de (I. T. Kolassa).
}

well-being of our distant ancestors (Seligman, 1971; Öhman, 1993). Support for the evolution-driven preparedness theory comes from research indicating that, for example, ancestral stimuli (e.g., spiders, snakes, and heights) represent potent conditioned stimuli even in non-phobic subjects (Öhman and Soares, 1998; Mineka and Öhman, 2002; Öhman and Mineka, 2003), and that ancestral stimuli involuntarily attract the attention of spider phobic subjects (Miltner et al., 2004).

Vision is the key sensory system for environmental orientation in humans (Colavita, 1974). Thus, it is obvious that visual cues play a major role in identifying spiders (Öhman and Soares, 1994, 1998; Miltner et al., 2004), and it is not surprising that the fear reaction of spider phobic subjects is predominantly mediated through visual cues, which are processed with high priority and selectivity (Miltner et al., 2004; Kolassa et al., 2005, 2006).

However, if spiders are ancestral stimuli with phylogenetic roots, the phenomenon should be so 
universal that the loss of sight should be no limiting factor in the development of spider phobia as long as the subject is capable of any representation of a spider. We were interested to what extent the development of spider phobia is dependent on these visual cues and whether spider phobia can occur in subjects who never had the ability to see, i.e. congenitally blind persons.

\section{Methods}

The spider questionnaire (SPQ; Klorman et al., 1974) is a 31-item questionnaire that reliably identifies subjects with spider phobia. Women scoring $\geq 21$ and men scoring $\geq 15$ on the SPQ correspond to the 95th percentile and are considered to be spider-fearful (Klorman et al., 1974). Because some items cannot be answered by blind persons, the questionnaire was reduced to 21 items $\left(\mathrm{SPQ}_{\mathrm{blind}}\right)$ that could be answered by sighted and non-sighted persons. Based on an interview with a blind person, items $3,4,6,10,17$, $19,20,21,24$, and 27 were deleted. These were items such as Item 4 "I dislike looking at pictures of spiders in a magazine." and Item 6 "I enjoy watching spiders build webs". Two items were rephrased. Item 11 "When I see a spider, I feel tense and restless" was rephrased to "When I am confronted with a spider, I feel tense and restless". Item 13 "I feel sick when I see a spider" was rephrased to "I feel sick when I think of a spider".

The reliability of the SPQ blind was assessed in a pilot study with 37 sighted individuals (age $M=21.8$ years, S.D. $=1.9 ; 13$ male, 24 female) including 13 persons (age $M=21.1$ years, S.D. $=1.8 ; 1$ male, 12 female) with spider phobia. Participants were students of the University of Jena recruited by newspaper advertisement, on campus bulletin boards and in lectures. Recruitment specifically targeted spider phobic persons and non-phobic control subjects. Spider phobic individuals fulfilled DSM-IV criteria of spider phobia as measured by the Structured Clinical Interview for DSM-IV (SCID-I; Wittchen et al., 1997). The $\mathrm{SPQ}_{\text {blind }}$ was highly correlated with the SPQ, Kendall's Tau, $\tau=0.89, P<0.01$, and had a Cronbach's $\alpha$ of 0.91, whereas the original SPQ had a Cronbach's $\alpha$ of 0.95 .

Participants in the main study comprised 33 sighted $(13$ male, 20 female, mean age $=32.0$ years, S.D. $=11.5)$ and 27 congenitally blind individuals (14 male, 13 female, age $M=38.5$ years, S.D.=11.6). Sighted participants were recruited as above, and blind participants were recruited via inquiries and via e-mail announcements at regional and nationwide associations of the blind, schools for the blind, and various magazines for the blind. Recruitment did not target specifically spider-fearful and non-fearful participants. However, it was explained to subjects that the aim of the investigation was to investigate spider phobia in blind and sighted persons. Both groups were a sample of convenience.

Sighted participants completed the SPQ and in addition the modified items 11 and 13 (see above). Blind participants completed the $\mathrm{SPQ}_{\text {blind. }}$. The $\mathrm{SPQ}$ blind score was calculated for sighted persons by removing the appropriate items from the SPQ and using the rephrased items 11 and 13 instead of the original ones. All subjects completed the trait version of the German translation of the State-Trait Anxiety Inventory (STAI-G; Laux et al., 1981). The STAI measures general anxiety and has been shown to be suitable for blind subjects (Mastro et al., 1985). In addition, participants completed a modified version of the Spider Anxiety Screening (SAS; Rinck et al., 2002), which aims to identify the diagnostic criteria of specific (spider) phobia according to DSM-IV. One of the four items, which explicitly relies on the visual system ("I get nervous and my heart races at the sight of a spider"), was changed (to "I get nervous and my heart races when I am confronted with a spider").

\section{Results}

On the basis of the SPQ, seven sighted persons (1 male, 6 female; age $M=28.7$ years, S.D. $=14.9)$ were classified as spider-fearful and 26 sighted persons were classified as non-fearful (12 male, 14 female; age $M=32.7$ years, S.D. $=10.8$ ); see Tables 1 and 2 for questionnaire values. The seven sighted persons classified by the SPQ as spider-fearful were also classified by the adapted SAS as spider-fearful and thus fulfilled DSM-IV criteria of spider phobia.

$\mathrm{SPQ}_{\text {blind }}$ scores did not differ significantly between sighted and blind non-phobic persons, $t(50)=-0.52$, $P=0.61$. Furthermore, there was no difference in state anxiety levels between the non-phobic sighted and non-phobic blind group, $t(50)=0.70, P=0.49$, and between the sighted non-phobic and spider phobic

Table 1

Mean questionnaire values (M), standard deviations (S.D.) and minimum/maximum (range) for sighted and blind persons

\begin{tabular}{|c|c|c|c|c|c|c|}
\hline \multirow[t]{2}{*}{ Questionnaire } & \multicolumn{3}{|c|}{ Sighted group } & \multicolumn{3}{|c|}{ Blind group } \\
\hline & $M$ & S.D. & Range & $M$ & S.D. & Range \\
\hline SPQ & 8.80 & 8.84 & 026 & & & \\
\hline STAI & 37.52 & 8.24 & 2255 & 38.52 & 10.55 & $20 \quad 59$ \\
\hline SPQ blind & 5.35 & 5.78 & $\begin{array}{ll}0 & 17\end{array}$ & 2.75 & 2.94 & 013 \\
\hline SAS blind & 8.00 & 8.30 & $\begin{array}{ll}0 & 24\end{array}$ & 4.33 & 5.53 & $0 \quad 19$ \\
\hline
\end{tabular}

Note. Missing fields were not applicable. 
Table 2

Mean questionnaire values $(M)$, standard deviations (S.D.) and minimum/maximum (range) for each group

\begin{tabular}{|c|c|c|c|c|c|c|c|c|c|c|}
\hline \multirow[t]{2}{*}{ Questionnaire } & \multicolumn{3}{|c|}{ Sighted non phobic controls } & \multicolumn{3}{|c|}{ Blind non phobic controls } & \multicolumn{3}{|c|}{ Sighted phobics } & \multirow{2}{*}{$\frac{\text { Blind phobic person }}{M}$} \\
\hline & $M$ & S.D. & Range & $M$ & S.D. & Range & $M$ & S.D. & Range & \\
\hline SPQ & 4.73 & 5.05 & $0 \quad 18$ & & & & 23.08 & 1.89 & 2126 & \\
\hline STAI & 36.69 & 8.62 & 2255 & 38.58 & 10.75 & 2059 & 40.57 & 6.21 & 3252 & 37 \\
\hline SPQ blind & 2.72 & 2.86 & $\begin{array}{ll}0 & 10\end{array}$ & 2.36 & 2.15 & 07 & 15.12 & 1.6 & 1317 & 13 \\
\hline SAS blind & 4.38 & 4.81 & $\begin{array}{ll}0 & 18\end{array}$ & 3.77 & 4.79 & $\begin{array}{ll}0 & 15\end{array}$ & 21.43 & 1.90 & 1924 & 19 \\
\hline
\end{tabular}

Note. Missing fields were not applicable.

groups, $t(31)=-1.11, P=0.28$. With the exception of one sighted spider phobic person (STAI above norm 51), all spider phobic participants had normal trait anxiety levels (Fig. 1).

The lowest score a sighted person classified with the SPQ as spider phobic reached in the SPQ blind was 13. This suggests that a person reaching this value in the blind group might also show symptoms of spider phobia, as the sighted spider-fearful person with the same score did. This threshold value was reached by one female congenitally blind person (here called H.K., $\mathrm{SPQ}_{\text {blind }}=13$ ). Her $\mathrm{SPQ}$ blind score was independent of general anxiety, since her STAI score of 37 was average (Fig. 1).

A detailed, semi-structured interview was conducted with H.K. in which she was questioned about the cause of her blindness, her own causal explanation of her spider phobia, incidents that may have contributed to her spider phobia, negative experiences with spiders or other insects, and physical reactions in response to spiders. The Structured Clinical Interview for DSM-IV (SCID-I; Wittchen et al., 1997) confirmed that the blind phobic subject met DSM-IV (American Psychiatric Association, 1994) criteria for specific spider phobia. Furthermore, the following information was obtained:

At the time of the interview, H.K. was 39 years old, having grown up in West Germany and finished a special school for the blind with a German "Hauptschule" degree after 9 years of schooling. The origin of her congenital blindness is unknown.

H.K. reported that spiders were described to her by sighted persons as ugly animals. However, she thought that this did not contribute to her spider phobia. Her personal explanation for her spider phobia was twofold: on the one hand she experienced spiders as an uncontrollable risk because they are difficult to localize. On the other hand, she associated spiders with dirt because "you never know where they have been before". However, she did not associate other insects with such thoughts such as, for example, house flies. However, H.K. reported that she generally feared and loathed insects. Besides other insects, she did not fear animals. Yet, she also feared thunderstorms and the noise of building sites. None of her parents or siblings were spider phobic; however, her mother was fearful of mice.

H.K. reported an incident during her childhood that she felt contributed to her spider phobia: while playing in the attic as a 4-year-old, she accidentally touched a spider net and found this extremely frightening and disgusting.

As physiological response, to a spider, she reported heart beating, feeling warm, and sweating. For her, the most important disgusting features of spiders were the many long legs, the hairy body and the cobwebs. The most important fear-inducing characteristics were the potential poisonousness of spiders as well as the potential transmission of diseases through germs. She reported having a very good visual image of a spider from the description of others and from manipulating model of spiders together with models of other insects in biology class.

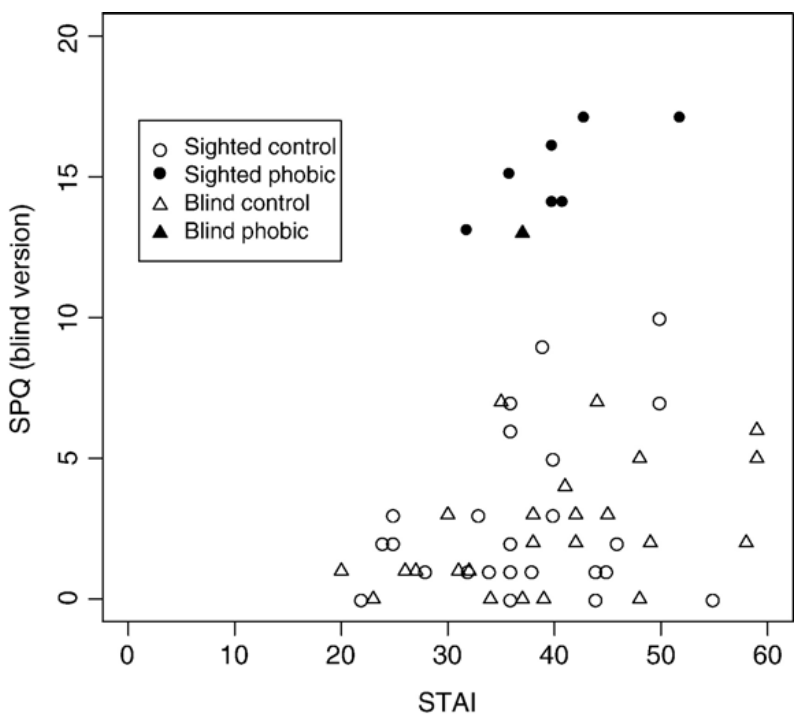

Fig. 1. SPQ blind and STAI trait scores. Seven sighted and one congenitally blind subject reached a score $\geq 13$ in the $\mathrm{SPQ}_{\mathrm{blind}}$ and thus fulfilled the criterion for spider phobia. Only one of the sighed spider phobic subjects scored above norm (51) in the STAI, indicating increased general anxiety. 


\section{Discussion}

We found a congenitally blind person who fulfilled the criteria of spider phobia given by an adapted version of the SPQ as well as DSM-IV, demonstrating that sight is not necessarily a prerequisite of spider phobia. In addition, this subject did not show elevated trait anxiety. Thus, the observed spider phobia was not due to a generally enhanced anxiety level perhaps due to her disability, which is in accordance with earlier findings showing no enhanced anxiety levels in blind athletes (Mastro et al., 1985).

The subject's having a visual image of a spider is in accordance with findings that congenitally blind subjects are capable of visual imagery (Kaski, 2002). It is possible that the subject gained such a visual image of a spider derived from touch (see also Vecchi, 1998; Aleman et al., 2001). Indeed, she reported haptic exploration of a spider model and contact with a spider net during childhood which she found extremely frightening and disgusting. Results imply a tactile contribution to spider phobia that has been relatively neglected so far, i.e. not only the visual features of a spider induce fear but also the idea of feeling a spider.

From an evolutionary perspective, one would have expected similar prevalence rates of spider phobia in congenitally blind and sighted persons because if spiders are ancestral stimuli with phylogenetic roots, the phenomenon should be so universal that the loss of sight should be no limiting factor in the development of spider phobia as long as the subject is capable of any representation of a spider. However, in the present study, a prevalence rate of spider phobia of $21.2 \%$ was observed in the sighted group, whereas in the congenitally blind group a much lower prevalence rate of $3.7 \%$ was found. This might suggest that the role of visual features in spider phobia may indeed be of paramount importance, given the much higher prevalence in sighted individuals. Nonetheless, a key finding of the present study is that phobia can apparently also be induced by representations constructed from semantic (propositional) information in combination with visual imagery and somatosensory experience (touch). It might also be interesting to gather information on the representations of spiders in blind persons and to investigate in a follow-up study with more subjects whether blind participants with better spider representations also have higher spider fear values.

\section{Acknowledgements}

We thank Carola Arfeller for valuable support in conducting the study and Stephan Kolassa for helpful comments on the manuscript. We are also indebted to "Deutscher Verein der Blinden und Sehbehinderten in Studium und Beruf e.V. (DVBS)", "Nordrhein-Westfälischer Landesverband des Bundes zur Förderung Sehbehinderter", "Berufliches Bildungszentrum Halle", "Berufliches Bildungszentrum Würzburg", "Blindenund Sehbehindertenverein Jena", and the newspapers "Horus" and "Umwelt-Echo" for supporting this study.

\section{References}

Aleman, A., van Lee, L., Mantione, M.H.M., Verkoijen, I.G., de Haan, E.H.F., 2001. Visual imagery without visual experience: evidence from congenitally totally blind people. Cognitive Neuroscience and Neuropsychology 12, 26012604.

American Psychiatric Association, 1994. Diagnostic and Statistical Manual of Mental Disorders: DSM IV. APA, Washington DC.

Colavita, F.B., 1974. Human sensory dominance. Perception \& Psychophysics 16, 409412.

Kaski, D., 2002. Revision: is visual perception a requisite for visual imagery? Perception 31, 717731.

Klorman, R., Weerts, T.C., Hastings, J.E., Melamed, B.G., Lang, P.J., 1974. Psychometric description of some specific fear question naires. Behaviour Research and Therapy 5, 401409.

Kolassa, I. T., Musial, F., Mohr, A., Trippe, R.H., Miltner, W.H.R., 2005. Electrophysiological correlates of threat processing in spider phobics. Psychophysiology 42, 520530.

Kolassa, I. T., Musial, F., Kolassa, S., Miltner, W.H.R., 2006. Event related potentials when identifying or color naming threatening schematic stimuli in spider phobic and non phobic individuals. BMC Psychiatry 6, 38.

Laux, L., Glanzmann, P., Schaffner, P., Spielberger, C.D., 1981. Das State Trait Angstinventar (STAI G). Beltz Verlag, Weinheim.

Mastro, J., French, R., Henschen, K., Horvat, M., 1985. Use of the State Trait Anxiety Inventory for visually impaired athletes. Perceptual \& Motor Skills 61, 775778.

Miltner, W.H.R., Krieschel, S., Hecht, H., Weiss, T., 2004. Eye movements and behavioural responses to threatening and non threatening stimuli during visual search in phobic and non phobic subjects. Emotion 4, 323339.

Mineka, S., Öhman, A., 2002. Born to fear: non associative vs. associative factors in the etiology of phobias. Behaviour Research and Therapy 40, 173184.

Öhman, A., 1993. Fear and anxiety as emotional phenomena: clinical phenomenology, evolutionary perspectives and informa tion processing mechanisms. In: Lewis, M., Haviland, J.M. (Eds.), Handbook of Emotions. The Guilford Press, New York, pp. 511536.

Öhman, A., Mineka, S., 2003. The malicious serpent: snakes as a prototypical stimulus for an evolved module of fear. Current Directions in Psychological Science 12, 59.

Öhman, A., Soares, J.J.F., 1994. "Unconscious anxiety": phobic responses to masked stimuli. Journal of Abnormal Psychology 103,231240

Öhman, A., Soares, J.J.F., 1998. Emotional conditioning to masked stimuli: expectancies for aversive outcomes following nonrecog nized fear relevant stimuli. Journal of Experimental Psychology General 127, 6982 . 
Rinck, M.M., Bundschuh, S., Engler, S., Müller, A., Wissmann, J., Ellwart, T., Becker, E.S., 2002. Reliabilität und Validität dreier Instrumente zur Messung von Angst vor Spinnen. Diagnostica 48, 141149.

Seligman, M.E.P., 1971. Phobias and preparedness. Behavior Therapy 2,307320 .
Vecchi, T., 1998. Visuo spatial imagery in congenitally totally blind people. Memory 6,91 102 .

Wittchen, H. U., Wunderlich, U., Gruschwitz, S., Zaudig, M., 1997. Strukturiertes Klinisches Interview für DSM IV [Structured Clinical Interview for DSM IV]. Hogrefe, Göttingen. 